\title{
Accurate prediction of different forecast horizons wind speed using a recursive radial basis function neural network
}

\author{
M. Madhiarasan (1)
}

\begin{abstract}
Environmental considerations have prompted the use of renewable energy resources worldwide for reduction of greenhouse gas emissions. An accurate prediction of wind speed plays a major role in environmental planning, energy system balancing, wind farm operation and control, power system planning, scheduling, storage capacity optimization, and enhancing system reliability. This paper proposes an accurate prediction of wind speed based ona Recursive Radial Basis Function Neural Network (RRBFNN) possessing the three inputs of wind direction, temperature and wind speed to improve modern power system protection, control and management. Simulation results confirm that the proposed model improves the wind speed prediction accuracy with least error when compared with other existing prediction models.
\end{abstract}

Keywords: Recursive radial basis function neural network, Prediction, Horizons, Generic, Wind speed

\section{Introduction}

Environmental degradation and depletion of conventional energy have helped direct attention towards wind energy. The dual aims of global reduction of $\mathrm{CO}_{2}$ emissions and improving energy security (being the energy policy goal in many countries) coincide with the increasing use of wind energy for electricity generation. Wind speed prediction is a noted problem and hot topic in research due to the time varying and volatile nature of wind.

An Artificial Neural Network (ANN) is a nonlinear information processing system, inspired by the biological nervous system [1] and constructed based on interconnected elementary processing devices called neurons. The ANN is widely used for various applications because of certain special features such as its good self learning ability, adaptability, real-time operation, fault tolerance, simple implementation and cost effectiveness. ANNs can be classified as feed-forward and feedback (recurrent) networks. A network arranged in layers with no feedback

Correspondence: mmadhiarasan89@gmail.com

Independent Researcher, No: 14, Uzhaippaali Street, Annai Anjugam Nagar, Ayapakkam, Chennai, Tamil Nadu Pin Code- 600077, India path is called a feed-forward network, e.g., Back propagation network, Multi-layer perceptron, Radial basis function network, etc. [1]. A network with a feedback path that occurs between the layers (or) within the layers is called feedback network, e.g., ELMAN, Hopfield, Boltzmann machine, etc. The Radial basis function network is a multi-layer feed-forward network and is generally applied for pattern recognition and function approximation applications. The network arrangment is from the input layer, through one (or) more hidden layers, to the output layer.

Small variations of wind speed can lead to significant change to the operation of wind driving systems, and hence, wind speed prediction is required for the following reasons:

1) To aid planning and control of a power system and wind farm.

2) Effective integration of wind power to the electrical power grid.

3) Reliable and high quality operation of the power system.

4) To meet the requirement of a system with low spinning reserve.
Springer Open

( ) The Author(s). 2020 Open Access This article is licensed under a Creative Commons Attribution 4.0 International License, which permits use, sharing, adaptation, distribution and reproduction in any medium or format, as long as you give appropriate credit to the original author(s) and the source, provide a link to the Creative Commons licence, and indicate if changes were made. The images or other third party material in this article are included in the article's Creative Commons licence, unless indicated otherwise in a credit line to the material. If material is not included in the article's Creative Commons licence and your intended use is not permitted by statutory regulation or exceeds the permitted use, you will need to obtain permission directly from the copyright holder. To view a copy of this licence, visit http://creativecommons.org/licenses/by/4.0/. 
5) To minimize the operating cost of wind power generation.

Much research has attempted and proposed ANNbased wind speed prediction models, and a review of relevant work is given below.

Anurag More et al. [2], proposed cascade correlation and back propagation algorithms-based neural networks for short-term wind speed prediction. Results reveal that the approach achieves $4.7 \%$ of MSE for cascade correlation and $4.5 \%$ of MSE for back propagation. Perez Li era et al. [3], develop a wind speed prediction model based on a BP (Back Propagation) algorithm, and achieve 0.00056 of MSE for 20 mins ahead wind speed prediction.

Selcuk Nogay H et al. [4], analyze various ANN-based models for short-term wind speed forecasting. Results suggest that the proposed model with 60 neurons achieves successful forecasting with 0.378088 of MSE and 0.970490 of approximation values. Vigneswaran $\mathrm{T}$ and Dhivya S [5], investigate and predict the wind speed for $18 \mathrm{~h}$ ahead of time scale by means of five ANN techniques, namely FFBP, CFBP, GRNN, PNN, and KNN. Among the five, GRNN is found to be superior and optimal due to the lowest MSE (2.8568\%).

Chuanan Yao et al. [6], present a comparison of three wavelet neural networks for short-term wind speed forecasting. The first two models are based on combinations of wavelet transform and neural network, namely Compact Wavelet Neural Network (CWNN) and Loose Wavelet Neural Network (LWNN), while the third model is a hybrid method based on the CWNN and LWNN model. Forecasting performance proves that the third model is more accurate than the other two despite the drawback of lower computational efficiency. The MAE, RMSE and MAPE values of the LCWNN model are $0.426 \mathrm{~m} / \mathrm{s}, 0.468$ $\mathrm{m} / \mathrm{s}$, and $11.82 \%$, respectively. Gnana Sheela K and Deepa $\mathrm{S} \mathrm{N}$ [7], use a radial basis function network-based wind speed prediction and introduce a new algorithm to search the proper hidden neurons. The suggested 101 various criteria are validated based on the error values of MSE, MAE, and MAPE, and the minimal error value is considered as the best solution among the 101 criteria (i.e. MSE of 2.5e-08, MAPE of 3.65e-04 and MAE of 1.97e-05). Ramesh Babu N and Arulmozhivarman P [8], use a hybrid method composed of Wavelet Transform and Neural Network (WTNN). WT is used to decompose the time series data in the different consecutive data series, and the data is given to the Neural Network (NN) to forecast future wind speed. The MSE, RMSE and mean average error are reduced by $7.38 \%, 12.7 \%$, and $8.91 \%$ respectively compared with BPNN. Xinrong Liu et al. [9], develop Relevance Vector Machine (RVM) and Empirical Mode Decomposition (EMD) based models. EMD decomposes complex nonlinear and non-stationary signals into some stable layers and is an effective method for analyzing wind speed. A Bayesian estimation theory-based RVM model is superior to SVM in terms of reduced computational complexity. The results confirm that the EMD-RVM-based model obtains 11.18 of MAPE, and is better than RVM.

Qinghua $\mathrm{Hu}$ et al. [10], propose a pattern-based approach for short-term prediction and in order to perform better than the clustering based approach. The Generalized Principal Component Analysis (GPCA) method is adopted to find the hidden sub spaces and their dimensions. An ensemble prediction method with time scales from 1 to $24 \mathrm{~h}$ ahead prediction outperforms other methods, and the proposed Ensemble GPCA achieves 5.3305 of MSE. Ramesh Babu N and Arulmozhivarman P [11], develop a very short-term forecasting model based on Nonlinear Auto regression with exogenous input (NARX), and achieves 0.2008 and 0.4481 of MSE and RMSE, respectively. Wenyu Zhang et al. [12], work on a hybrid forecasting model based on SSA and intelligent optimized algorithms. This method consists of decomposition and reconstruction of SSA and hence results in better evaluation of forecasting performance in a time series. SVM is found to be unsatisfactory, but two other forecasting methods (ANN, ARIMA) are still suitable for short-term prediction of wind speed (4-7 h).

Madhiarasan M and Deepa S N [13], develop 151 different criteria for the proper selection of hidden neurons in Improved Back Propagation Networks (IBPN) for wind speed forecasting. The results showed that the criterion $(8 n-4) /(n-4)$ with 36 hidden neurons achieves better MSE of 5.8672e-08, MAE of 4.0908e-05, MRE of $1.1919 \mathrm{e}-05$ and RMSE of 2.4222e-04 than other proposed criteria. Hence, the suggested novel criterion improves forecasting accuracy. Other related work on developing wind speed forecasting models has also been reported in [14-22].

Dehua Zheng et al. [23], considered double stage hierarchical ANFIS-based wind power forecasting for the short term horizon for micro grid energy management. A limitation is that the forecasting error is high. Hao Chen et al. [24], performed wind power forecasting based on GARCH type models, and the limitation accuracy was improved.

From the above review and as illustrated in [25], it is clear that various heuristics exist. Further research is nevertheless still required. Based on the existing approaches, it is clear that generalized and highly accurate wind speed prediction is still challenging. Some forecasting models obtain better results only for the considered forecast horizon but fail to generalize for other horizons. This paper proposes an accurate wind speed prediction model based on a Recursive Radial Basis Function Neural Network (RRBFNN). The main aim is to achieve better prediction accuracy, with reduced minimal error, than other existing methods.

Enhanced prediction accuracy with small evaluation metrics is advantageous. The main novelty of the paper 
is the proposal of a novel RRBFNN for the prediction of wind speed. Compared to the radial basis function neural network, the proposed RRBFNN adopts a different recursive learning algorithm. Hence, errors are minimized further leading to optimal forecasting performance. The main advantages are the provision of highly accurate prediction of wind speed with minimal training computational time when compared to other typical methods, and being generic for various forecasting horizons such as very short, short, medium and long term.

\section{Proposed recursive radial basis function neural networks}

\subsection{Problem description}

In order to achieve better generalization for wind speed prediction, the input and output are to be modeled and the hidden neuron number should be appropriately selected for the neural network design. In the current scenario many prediction research fields have been heuristic. While numerous researchers have developed prediction models for accurate wind speed prediction, no perfect model has been achieved. However, an accurate wind speed prediction model based on RRBFNN for a long-term forecast horizon (1 day to 1 week ahead or more) is presented in this paper.

The proposed system is selected for the following reasons:

(i) Ability to overcome the local minima.

(ii) Resilient against a poor training set.

(iii) Fast training.

(iv) Improvement of convergence speed.

(v) Ease of implementation and compact structure.

\subsection{Proposed system description}

RRBFNN is a multi-layer feed-forward neural network comprising an input layer, hidden layer and output layer. In RRBFNN, weights are recursively updated to achieve minimal output error. The proposed RRBFNN is superior to back propagation feed-forward neural networks and radial basis function networks in terms of convergence and accuracy. The input layer outputs are obtained by computing the distance between the inputs and hidden layer centers, and are transferred to the hidden layer in a nonlinear form. The hidden layer has a large dimension because all the input layer neurons are connected directly to it, and each hidden neuron in the hidden layer has parameters such as width and center position. Each hidden neuron in the hidden layer has an activation function, and generally a Gaussian activation function is applied to RRBFNN. The adjustment of the network limits such as spread value helps to fine tune the Gaussian recursive radial basis function. The outputs of the hidden layer are a weighted form of the input layer outputs and are transferred to the output layer in a linear form. The weights are updated recursively in order to obtain the minimum output error, and the weight updating process uses the gradient descent rule.

Neural Networks with many hidden layers cause the following problems:

(i) Increased complexity of the network.

(ii) Extremely hard to train based on the weight values.

(iii) Increased computational time.

(iv) Possibility of encountering the over-fitting problem.

Hence, the presence of several hidden layers leads to unsatisfactory and poor performance. Therefore, the proposed RRBFNN only has one hidden layer, which is sufficient to approach any continuous function with the least complexity and improved output performance. A single hidden layer with various hidden neurons is employed for performance analysis of the proposed model.

\subsection{Proposed wind speed prediction model}

The proposed RRBFNN based wind speed prediction model has inputs of Wind direction $\left(W D_{w}\right)$, Temperature $\left(T D_{w}\right)$ and Wind speed $\left(N_{w}\right)$, and the input layer is constructed based on the three input neurons. The output layer has a single output neuron, i.e., the predicted wind speed. The architecture of the proposed RRBFNN model is shown in Fig. 1, and the inferred input and output target vector pairs are described in Table 1. As shown in Fig. 1, each layer performs independent computation on the received data and the computed results are passed to the next layer and finally the network output is determined.

According to Fig. 1, the input and output vectors are given as

$$
\begin{aligned}
X & =\left[W D_{W}, T D_{w}, N_{w}\right] \\
Y & =\left[N_{p w}\right]
\end{aligned}
$$

The weight vectors between the hidden to output vectors are

$$
W=\left[W_{1}, W_{2}, \ldots ., W_{m}\right]
$$

and the Gaussian activation function can be expressed as

$$
f\left(Y_{\text {in }}\right)=e^{\left(-Y_{\text {in }}^{2}\right)}
$$

where $Y_{\text {in }}$ is the net output of RRBFNN and can be given as

$$
Y_{\text {in }}=\sum_{i=1}^{n} f\left(\left\|X-C_{i}\right\|\right) * W_{i k}, k=1,2, \ldots ., m
$$

where $n$ is the number of hidden neurons, $X$ is the input 


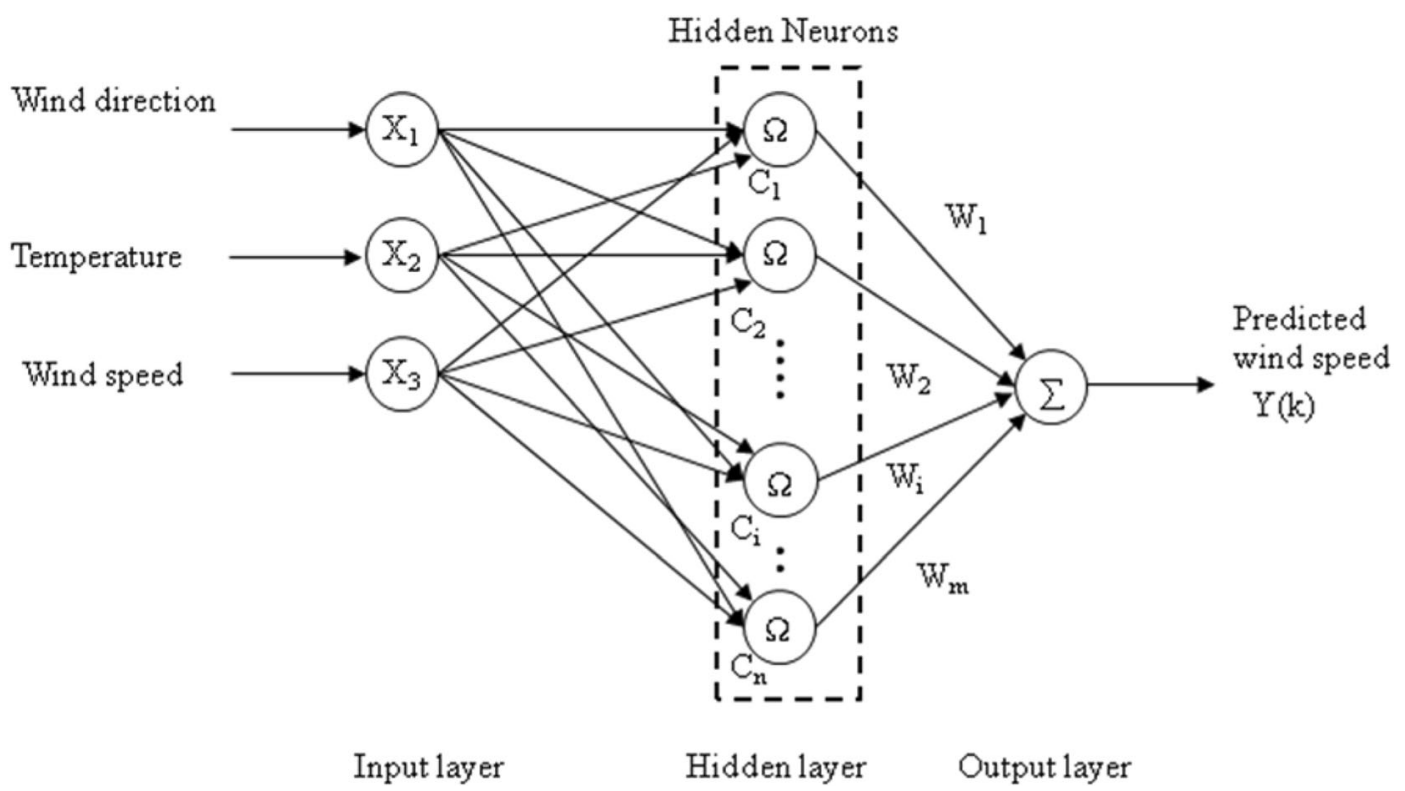

Fig. 1 Architecture of the proposed RRBFNN model

vector and $C_{i}$ is the $i^{\text {th }}$ center node in the hidden layer. $\left\|X-C_{i}\right\|$ is the Euclidean distance between $C_{i}$ and $X, f$ the activation function (Gaussian function) and $W_{i k}$ the weights between the hidden and output layers.

\subsubsection{Data collection}

Real-time data was collected from the Suzlon Energy Private Limited from January 2016 to December 2018. Wind direction (Degree), Temperature $\left({ }^{\circ} \mathrm{C}\right)$ and Wind speed $(\mathrm{m} / \mathrm{s})$ are the inputs to the proposed RRBFNN and network output is the predicted wind speed $(\mathrm{m} / \mathrm{s})$. The proposed RRBFNN model is designed using 10,000 sets of data. Table 2 shows the used input parameters of the RRBFNN model, and Table 3 shows the collected realtime input data sample.

\subsubsection{Data normalization}

Normalization (or scaling) is mandatory for dealing with real-time data having different ranges and units. Therefore, normalization is used to scale the real-time data within the range of 0 to 1 to help achieve more accurate

Table 1 Input and output variables of the proposed neural network model

\begin{tabular}{llll}
\hline $\begin{array}{l}\text { Input } \\
\text { Variables }\end{array}$ & Description & $\begin{array}{l}\text { Output } \\
\text { Variable }\end{array}$ & Description \\
\hline$X_{1}$ & $\begin{array}{l}\text { Wind Direction } \\
\left(W D_{w}\right)\end{array}$ & $Y$ & $\begin{array}{l}\text { Predicted wind speed } \\
\left(N_{p w}\right)\end{array}$ \\
$X_{2}$ & $\begin{array}{l}\text { Temperature } \\
\left(T D_{w}\right)\end{array}$ & \\
$X_{3}$ & Wind Speed $\left(N_{w}\right)$ & \\
\hline
\end{tabular}

numeric computation and enhance output accuracy. The min-max normalization technique is used for the proposed model as

$$
X_{i}^{\prime}=\left(\frac{X_{i}-X_{\min }}{X_{\max }-X_{\min }}\right)\left(X_{\max }^{\prime}-X_{\min }^{\prime}\right)+X_{\min }^{\prime}
$$

where $X_{i}^{\prime}$ and $X_{i}$ are the scaled and actual input data, respectively. $X_{\min }$ and $X_{\max }$ are the respective minimum and maximum input data, whereas $X_{\min }^{\prime}$ and $X_{\max }^{\prime}$ are the minimum and maximum target values, respectively.

\subsubsection{Proposed neural network design}

The proposed RRBFNN design parameters include the dimensions and epochs as shown in Table 4. The presented neural network design has three input neurons (wind direction, temperature and wind speed), one hidden layer with varying hidden neurons between 1 to 50 , and one output neuron (predicted wind speed).

The input layer and hidden layer are interconnected by means of a hypothetical connection. The hidden layer has a Gaussian function, and the hidden layer and output layer are interconnected by means of the weighted connections. The output layer has a linear function. The weights are updated recursively to the RRBFNN to

Table 2 Inputs parameters for RRBFNN model

\begin{tabular}{llll}
\hline S. No & Input Parameter & Units & Range of Parameter \\
\hline 1 & Wind Direction & Degree & $0.1-355$ \\
2 & Temperature & Degree. Celsius & $21-37$ \\
3 & Wind Speed & $\mathrm{m} / \mathrm{s}$ & $0.3-17$ \\
\hline
\end{tabular}


Table 3 Collected real-time inputs data sample (from Suzlon Energy Pvt. Ltd)

\begin{tabular}{llllll}
\hline $\begin{array}{l}\text { Temperature } \\
\left({ }^{\circ} \boldsymbol{C}\right)\end{array}$ & $\begin{array}{l}\text { Wind } \\
\text { direction } \\
\text { (Degree) }\end{array}$ & $\begin{array}{l}\text { Wind } \\
\text { speed } \\
(\boldsymbol{m} / \boldsymbol{s})\end{array}$ & $\begin{array}{l}\text { Temperature } \\
\left({ }^{\circ} \mathbf{C}\right)\end{array}$ & $\begin{array}{l}\text { Wind } \\
\text { direction } \\
(\text { Degree) }\end{array}$ & $\begin{array}{l}\text { Wind } \\
\text { speed } \\
(\boldsymbol{m} / \mathbf{s})\end{array}$ \\
\hline 26.4 & 285.5 & 8.9 & 24.1 & 77.3 & 2.9 \\
25.9 & 285.5 & 8.6 & 24.1 & 83 & 1.1 \\
25.8 & 279.8 & 7.7 & 28.4 & 83 & 6.4 \\
26.1 & 286.9 & 6.9 & 26.8 & 105.5 & 7.6 \\
30.4 & 298.1 & 6.8 & 26.1 & 101.2 & 5.6 \\
32.4 & 277 & 5.9 & 25.8 & 122.3 & 4 \\
27.5 & 315 & 3.8 & 24.1 & 184.2 & 0.4 \\
26.6 & 299.5 & 1.9 & 25.8 & 336.1 & 2.4 \\
25.2 & 112.5 & 9.2 & 24.5 & 26.7 & 5.3 \\
26.4 & 111.1 & 15.9 & 23.2 & 157.5 & 2.4 \\
\hline
\end{tabular}

improve the convergence and produce minimal error. Training learns from the normalized data and the test for the stopping condition is the error reaching a negligible value.

\subsubsection{Training and testing of the proposed neural network}

A wind speed prediction model is developed based on the training data while the performance of the proposed model is evaluated using the testing data. The collected 10,000 real-time data is classified into training and testing sets, with $70 \%$ of the collected data $(7,000)$ used for the training phase and the remaining $30 \%(3,000)$ for the testing phase of the neural network. Network performance is computed by means of statistical error criteria.

\subsubsection{Sensible variation of the system}

Proper selection of hidden neurons in neural networks plays a major role in improving the quality and performance of the network. The performance of the proposed RRBFNN-based prediction model is analyzed with various hidden neurons between 1 to 50 by fixing all the other design parameters. The appropriate numbers of hidden neurons in the hidden layer are determined based on the minimal statistical errors.

Table 4 Parameters for RRBFNN

\begin{tabular}{ll}
\hline Parameters & Parametric Values \\
\hline Input neuron & $3\left[W D_{w}, T D_{w} N_{w}\right]$ \\
Number of hidden layers & 1 \\
Number of hidden neurons & 1 to 50 \\
Output neuron & $1\left[N_{p w}\right]$ \\
Number of epochs & 1000 \\
Spread & 3 \\
\hline
\end{tabular}

\section{Evaluation metrics}

The performance of the proposed wind speed prediction model is analyzed based on the statistical error criteria such as Mean Square Error (MSE), Root Mean Square Error (RMSE), Mean Absolute Error (MAE), Mean Relative Error (MRE) and Mean Absolute Percentage Error (MAPE) criteria. The statistical error criteria formulas are defined as follows:

$$
\begin{aligned}
& \text { MSE }=\frac{1}{N} \sum_{i=1}^{N}\left(Y_{i}^{\prime}-Y_{i}\right)^{2} \\
& \text { RMSE }=\sqrt{ } \frac{1}{N} \sum_{i=1}^{N}\left(Y_{i}^{\prime}-Y_{i}\right)^{2} \\
& \text { MAE }=\frac{1}{N} \sum_{i=1}^{N}\left(Y_{i}^{\prime}-Y_{i}\right) \\
& \text { MRE }=\frac{1}{N} \sum_{i=1}^{N}\left|\left(Y_{i}^{\prime}-Y_{i}\right) / \bar{Y}_{i}\right| \\
& \text { MAPE }=\frac{100}{N} \sum_{i=1}^{N}\left|\left(Y_{i}^{\prime}-Y_{i}\right) / Y_{i}\right|
\end{aligned}
$$

\begin{tabular}{|c|c|c|c|c|c|c|}
\hline $\begin{array}{l}\text { S. } \\
\text { No }\end{array}$ & $\begin{array}{l}\text { Hidden } \\
\text { neurons }\end{array}$ & MSE & MAPE & RMSE & MAE & MRE \\
\hline 1 & 1 & 3.5571 & 20.7127 & 1.8860 & 1.6104 & 0.2071 \\
\hline 2 & 3 & 0.1279 & 2.7643 & 0.3577 & 0.2240 & 0.0276 \\
\hline 3 & 5 & 0.0255 & 0.6760 & 0.1597 & 0.0548 & 0.0068 \\
\hline 4 & 8 & $1.0314 \mathrm{e}-04$ & 0.0819 & 0.0102 & 0.0068 & $8.1939 \mathrm{e}-04$ \\
\hline 5 & 10 & 0.0077 & 0.6401 & 0.0879 & 0.0534 & 0.0064 \\
\hline 6 & 12 & $1.1866 \mathrm{e}-08$ & $7.1056 \mathrm{e}-04$ & $1.0893 e-04$ & $5.5245 e-05$ & $7.1056 \mathrm{e}-06$ \\
\hline 7 & 14 & $1.0610 \mathrm{e}-08$ & $3.4082 \mathrm{e}-04$ & $1.0301 \mathrm{e}-04$ & $2.7612 \mathrm{e}-05$ & $3.4082 \mathrm{e}-06$ \\
\hline 8 & 16 & 0.0089 & 0.7797 & 0.0944 & 0.0650 & 0.0078 \\
\hline 9 & 20 & $4.0350 \mathrm{e}-05$ & 0.0172 & 0.0064 & 0.0014 & 1.7164e-04 \\
\hline 10 & 23 & $1.3678 \mathrm{e}-04$ & 0.0377 & 0.0117 & 0.0031 & $3.7663 e-04$ \\
\hline 11 & 25 & $1.5602 \mathrm{e}-09$ & $2.8722 \mathrm{e}-04$ & $3.9499 \mathrm{e}-05$ & $2.2331 \mathrm{e}-05$ & $2.8722 \mathrm{e}-06$ \\
\hline 12 & 28 & $2.7572 \mathrm{e}-04$ & 0.0522 & 0.0166 & 0.0042 & $5.2163 \mathrm{e}-06$ \\
\hline 13 & 32 & $1.5323 \mathrm{e}-09$ & $2.3008 \mathrm{e}-04$ & $3.9145 e-05$ & $1.8640 \mathrm{e}-05$ & $2.3008 \mathrm{e}-06$ \\
\hline 14 & 34 & $6.5638 \mathrm{e}-09$ & $5.3788 \mathrm{e}-05$ & $8.1017 e-05$ & $4.1820 \mathrm{e}-05$ & $5.3788 \mathrm{e}-07$ \\
\hline 15 & 36 & $1.3931 \mathrm{e}-08$ & 8.8433e-04 & 1.1803e-04 & $6.8755 e-05$ & 8.8433e-06 \\
\hline 16 & 40 & $1.9713 \mathrm{e}-08$ & $9.5805 e-04$ & $1.4040 \mathrm{e}-04$ & 7.7617e-05 & $9.5805 \mathrm{e}-06$ \\
\hline 17 & 42 & $3.3233 \mathrm{e}-04$ & 0.0323 & 0.0182 & 0.0026 & 3.2299e-04 \\
\hline 18 & 44 & $\begin{array}{l}1.6166 \mathrm{e}- \\
12\end{array}$ & $\begin{array}{l}1.0165 e- \\
05\end{array}$ & $\begin{array}{l}1.2715 \mathrm{e}- \\
06\end{array}$ & $\begin{array}{l}8.2352 \mathrm{e}- \\
07\end{array}$ & $\begin{array}{l}1.0165 \mathrm{e}- \\
07\end{array}$ \\
\hline 19 & 46 & $1.9161 \mathrm{e}-07$ & $8.6964 \mathrm{e}-04$ & $4.3774 \mathrm{e}-04$ & $7.0454 \mathrm{e}-05$ & $8.6964 \mathrm{e}-06$ \\
\hline 20 & 50 & 0.0012 & 0.0512 & 0.0346 & 0.0041 & $5.1218 \mathrm{e}-04$ \\
\hline
\end{tabular}

where $\mathrm{N}$ is the number of samples, and $Y_{i}^{\prime}, \bar{Y}_{i}$ and $Y_{i}$ are the actual, averaged actual and predicted outputs,

Table 5 Performance analysis of the proposed model with various hidden neurons 


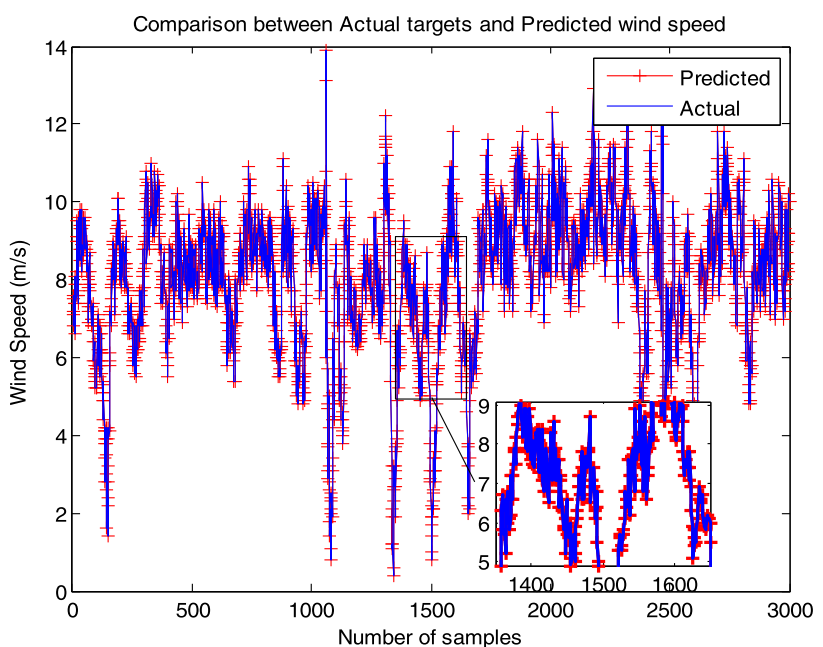

Fig. 2 Comparison between actual and predicted wind speed

respectively. Statistical errors are used to evaluate the quality of the predicted wind speed obtained by RRBFNN.

\section{Experimental results and discussion}

The proposed RRBFNN is run on an Acer laptop computer with Pentium (R) Dual Core processor running at 2.30GHZ with $2 \mathrm{~GB}$ of RAM. The real-time data is initially classified into training and testing sets. The training set is used in neural network learning and the testing set is used to compute the errors. The network performance is evaluated by statistical error calculation.

\subsection{Results analysis of the proposed prediction model}

The performance of the proposed wind speed prediction model with varying hidden neurons between 1 to 50 is shown in Table 5. It is observed from Table 5 that RRBFNN with 44 hidden neurons achieves the minimal statistical errors. Simulation results also reveal that the predicted wind speed is in the best agreement with the

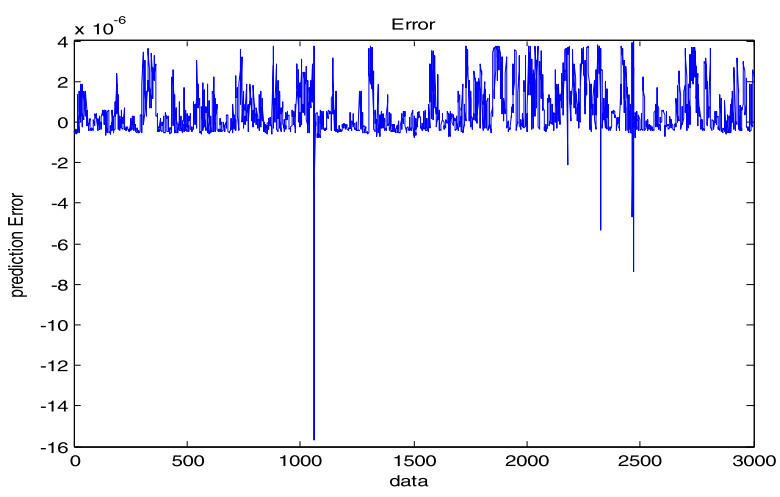

Fig. 3 Prediction Error
Table 6 Analysis of the proposed prediction model with different forecast horizons

\begin{tabular}{|c|c|c|c|}
\hline $\begin{array}{l}\text { S. } \\
\text { No }\end{array}$ & Different Forecast Horizons & $\begin{array}{l}\text { Performance } \\
\text { Metrics }\end{array}$ & $\begin{array}{l}\text { Parametric } \\
\text { Values }\end{array}$ \\
\hline \multirow[t]{5}{*}{1} & \multirow{5}{*}{$\begin{array}{l}\text { Very Short Term Prediction (Few } \\
\text { seconds to minutes ahead) }\end{array}$} & MSE & $4.0054 \mathrm{e}-07$ \\
\hline & & MAPE & 0.0102 \\
\hline & & RMSE & $6.3288 \mathrm{e}-04$ \\
\hline & & MAE & $5.4564 \mathrm{e}-04$ \\
\hline & & MRE & $1.0160 \mathrm{e}-04$ \\
\hline \multirow[t]{5}{*}{2} & \multirow{5}{*}{$\begin{array}{l}\text { Short Term Prediction ( } 30 \mathrm{~min} \text { to } 6 \mathrm{~h} \\
\text { ahead) }\end{array}$} & MSE & $4.6131 \mathrm{e}-11$ \\
\hline & & MAPE & $5.5382 \mathrm{e}-05$ \\
\hline & & RMSE & $6.7920 \mathrm{e}-06$ \\
\hline & & MAE & $4.4137 e-06$ \\
\hline & & MRE & $5.5382 \mathrm{e}-07$ \\
\hline \multirow[t]{5}{*}{3} & \multirow{5}{*}{$\begin{array}{l}\text { Medium Term Prediction ( } 6 \mathrm{~h} \text { to } \\
\text { ahead) }\end{array}$} & MSE & $1.5857 \mathrm{e}-11$ \\
\hline & & MAPE & $6.6481 \mathrm{e}-05$ \\
\hline & & RMSE & $3.9820 \mathrm{e}-06$ \\
\hline & & MAE & $2.8847 \mathrm{e}-06$ \\
\hline & & MRE & $6.6481 \mathrm{e}-07$ \\
\hline \multirow[t]{5}{*}{4} & \multirow{5}{*}{$\begin{array}{l}\text { Long Term Prediction (1 day to } 1 \\
\text { week or more ahead) }\end{array}$} & MSE & $1.6166 \mathrm{e}-12$ \\
\hline & & MAPE & $1.0165 \mathrm{e}-05$ \\
\hline & & RMSE & $1.2715 \mathrm{e}-06$ \\
\hline & & MAE & $8.2352 \mathrm{e}-07$ \\
\hline & & MRE & $1.0165 \mathrm{e}-07$ \\
\hline
\end{tabular}

measured values. Based on the proposed wind speed prediction model, the comparison between 3000 samples of actual and predicted wind speeds is shown in Fig. 2, where some parts are zoomed for better clarity. The variations of the prediction error with the numbers of data samples are shown in Fig. 3. The effectiveness and generalization ability of the proposed RRBFNN with 44 hidden neurons is analyzed based on different forecast horizons as shown in Table 6. From Table 6, it can be seen that the proposed model accurately predicts the wind speed for different horizons. The proposed RRBFNN-based prediction model for long-term forecast horizon with 44 hidden neurons has lower minimal errors than other horizons. Compared to other wind speed prediction models shown in Table 7, the proposed model outperforms and achieves better minimal statistical errors. The analysis on the training computation time also reveals that the proposed RRBFNN requires less time (i.e. $72 \mathrm{~s}$ ) than that of other considered approaches. Therefore, the proposed RRBFNN offers better forecasting results as well performing better in terms of computation time. Further comparison of the performance metrics among the different wind speed prediction methods is given in Fig. 4 and the demonstrated merits of the proposed approach are (i) very effective minimum error and (ii) simple implementation. 
Table 7 Comparison of the different approaches

\begin{tabular}{|c|c|c|c|c|c|c|}
\hline $\begin{array}{l}\text { S. } \\
\text { No }\end{array}$ & $\begin{array}{l}\text { Various Wind Speed Prediction } \\
\text { Approaches }\end{array}$ & Methodology & Year & $\begin{array}{l}\text { Performance } \\
\text { Metrics }\end{array}$ & $\begin{array}{l}\text { Parametric } \\
\text { Values }\end{array}$ & $\begin{array}{l}\text { Training Computation } \\
\text { Time in sec }\end{array}$ \\
\hline 1 & Anurag More \& Deo M C Approach & $\begin{array}{l}\text { NN with Cascade } \\
\text { Algorithm }\end{array}$ & 1995 & MSE & 0.0015 & 280 \\
\hline 2 & Perez Li era et al. Approach & NN with BP Algorithm & 1998 & MSE & $6.3334 \mathrm{e}-04$ & 305 \\
\hline 3 & Selcuk Nogay $\mathrm{H}$ et al. Approach & MLP with BP Algorithm & 2012 & MSE & $1.7244 \mathrm{e}-05$ & 186 \\
\hline \multirow[t]{2}{*}{4} & \multirow[t]{2}{*}{ Vigneswaran T \& Dhivya S Approach } & \multirow[t]{2}{*}{ GRNN } & \multirow[t]{2}{*}{2012} & MSE & 0.0236 & \multirow[t]{2}{*}{253} \\
\hline & & & & MAPE & 1.1545 & \\
\hline \multirow[t]{3}{*}{5} & \multirow[t]{3}{*}{ Gnana Sheela K \& Deepa S N Approach } & \multirow[t]{3}{*}{ RBF } & \multirow[t]{3}{*}{2013} & MSE & $7.1052 \mathrm{e}-06$ & \multirow[t]{3}{*}{152} \\
\hline & & & & MAE & 0.0010 & \\
\hline & & & & MAPE & 0.0131 & \\
\hline \multirow[t]{3}{*}{6} & \multirow[t]{3}{*}{ Chuanan Yao et al. Approach } & \multirow[t]{3}{*}{ LCWNN } & \multirow[t]{3}{*}{2013} & MSE & 0.0070 & \multirow[t]{3}{*}{137} \\
\hline & & & & RMSE & 0.0834 & \\
\hline & & & & MAPE & 0.4408 & \\
\hline \multirow[t]{4}{*}{7} & \multirow{4}{*}{$\begin{array}{l}\text { Ramesh Babu N \& Arulmozhivarman P } \\
\text { Approach }\end{array}$} & \multirow[t]{4}{*}{ WT - NN } & \multirow[t]{4}{*}{2013} & MSE & $1.0656 \mathrm{e}-04$ & \multirow[t]{4}{*}{148} \\
\hline & & & & RMSE & 0.0103 & \\
\hline & & & & MAE & 0.0029 & \\
\hline & & & & MAPE & 0.0361 & \\
\hline 8 & Qinghua Hu et al. Approach & Ensemble GPCA & 2014 & MSE & 0.0087 & 195 \\
\hline \multirow[t]{2}{*}{9} & \multirow{2}{*}{$\begin{array}{l}\text { Ramesh Babu N \& Arulmozhivarman P } \\
\text { Approach }\end{array}$} & \multirow[t]{2}{*}{ NARX } & \multirow[t]{2}{*}{2014} & MSE & 0.0335 & \multirow[t]{2}{*}{252} \\
\hline & & & & RMSE & 0.1830 & \\
\hline \multirow[t]{3}{*}{10} & \multirow[t]{3}{*}{ Wenyu Zhang et al. Approach } & \multirow[t]{3}{*}{ SSA } & \multirow[t]{3}{*}{2014} & MAE & 0.0733 & \multirow[t]{3}{*}{224} \\
\hline & & & & RMSE & 0.1031 & \\
\hline & & & & MAPE & 0.9050 & \\
\hline 11 & Madhiarasan M \& Deepa S N & IBPN & 2015 & MSE & $5.1014 \mathrm{e}-05$ & 140 \\
\hline & & & & RMSE & 0.0071 & \\
\hline & & & & MAE & $2.9832 \mathrm{e}-04$ & \\
\hline & & & & MRE & $3.6823 e-05$ & \\
\hline & & & & MAPE & 0.0037 & \\
\hline 12 & Proposed Approach & RRBFNN & & MSE & $1.6166 \mathrm{e}-12$ & 72 \\
\hline & & & & RMSE & $1.2715 \mathrm{e}-05$ & \\
\hline & & & & MAE & $8.2352 \mathrm{e}-07$ & \\
\hline & & & & MRE & $1.0165 \mathrm{e}-07$ & \\
\hline & & & & MAPE & $1.0165 \mathrm{e}-05$ & \\
\hline
\end{tabular}

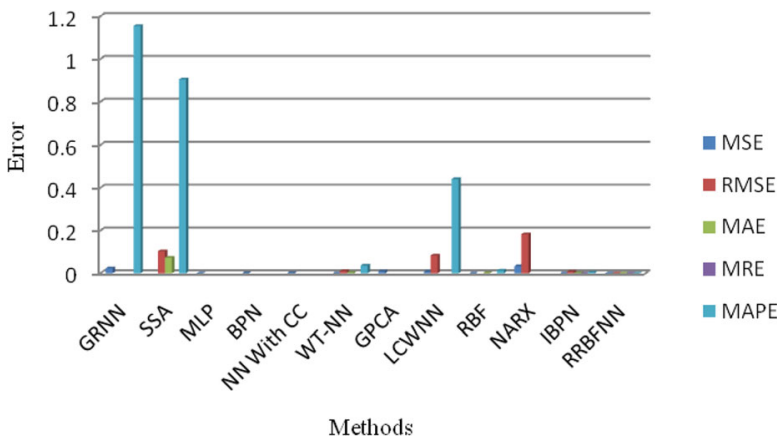

Fig. 4 Comparison of the performance metrics

\section{Conclusion}

A modern power system depends greatly on a renewable energy system in which a wind energy system is one of the prominent renewable energy resources for fulfilling future power demand. The protection and control of modern power system integration with a wind energy system can be improved by precise wind speed prediction. This paper proposes a novel Recursive Radial Basis Function Neural Network (RRBFNN) with three inputs for accurate wind speed prediction to aid the planning, integration and control of a power system and a wind farm. The presented wind speed prediction model is adapted and evaluated with 
real-time observations. Compared to other wind speed prediction models, the proposed RRBFNN model with 44 hidden neurons achieves better accuracy with minimal statistical errors such as MSE of 1.6166e-12, RMSE of $1.2715 \mathrm{e}-06$, MAE of 8.2352e-07, MRE of $1.0165 \mathrm{e}-07$ and MAPE of $1.0165 \mathrm{e}-05$. The implemented RRBFNN outperforms others for the longterm forecast horizon with the least error, better stability and generalization ability and faster convergence speed.

\begin{abstract}
Abbreviations
RES: Renewable energy system; RRBFNN: Recursive radial basis function neural network; ANN: Artificial neural network; BP: Back propagation; MSE: Mean square error; RMSE: Root mean square error; MAE: Mean absolute error; MRE: Mean relative error; MAPE: Mean absolute percentage error; WTNN: Wavelet transform and neural network; CWNN: Compact wavelet neural network; LWNN: Loose wavelet neural network; GPCA: Generalized principal component analysis; NARX: Nonlinear auto regression with exogenous input; SVM: Support vector machine; RAM: Random access memory; GRNN: Generalized regression neural networks; RVM: Relevance vector machine; IBPN: Improved back propagation networks; EMD: Empirical mode decomposition
\end{abstract}

\section{Acknowledgements}

The author is thankful to Suzlon Energy Private Limited for providing realtime observations to perform the research work.

\section{About the authors}

Dr. M. MADHIARASAN has completed his B.E degree in Electrical and Electronics Engineering in the year 2010 from Jaya Engineering College, Thiruninravur, under Anna University, Tamil Nadu, India, M.E. Degree in Electrical Drives and Embedded Control (Electrical Engineering) in the year 2013 from Anna University, Regional Centre, Coimbatore, under Anna University, Tamil Nadu, India and Ph.D (Electrical Engineering) in the year 2018 from Anna University, Tamil Nadu, India. He has worked as an Assistant Professor \& R \& D In-charge in the Department of Electrical and Electronics Engineering, Bharat Institute of Engineering and Technology, Hyderabad, India from 2018 to 2020. Presently, he is Independent Researcher. His Research areas include Renewable Energy System, Power Electronics and Control, Artificial Intelligence, Neural Networks, Modeling and Simulation, Optimization, IoT and Soft Computing.

\section{Author's contributions}

M. Madhiarasan is the corresponding author and 100\% contribution. The author(s) read and approved the final manuscript.

\section{Funding}

No Funding was received for this work.

\section{Availability of data and materials \\ Not applicable.}

\section{Competing interests}

I wish to confirm that there are no known conflicts of interest associated with this publication and there has been no significant financial support for this work that could have influenced its outcome.

Received: 6 January 2020 Accepted: 2 September 2020

Published online: 12 October 2020

\section{References}

1. Sivanandam, S. N., Sumathi, S., \& Deepa, S. N. (2008). Introduction to neural networks using Matlab 6.0, (1st ed., ). New Delhi: Tata McGraw Hill.

2. More, A., \& Deo, M. C. (1995). Forecasting wind with neural networks. Marine Structures, $16(1), 35-49$
3. Perez-Llera, C., Fernandez-Baizan, M. C., Feitoc, J. L., \& Gonzalez del Valle, V. (1998). Local short term prediction of wind speed: A neural network analysis, (pp. 124-129).

4. Selcuk Nogay, H., Akinci, T. C., \& Eidukeviciute, M. (2012). Application of artificial neural networks for short term wind speed forecasting in mardin, Turkey. Journal of Energy in Southern Africa, 23(4), 1-6.

5. Vigneswaran, T., \& Dhivya, S. (2012). Analyzing the probabilistic distribution of the predicted wind speed. International Journal of Computer and Information Technology, 01(02), 88-93.

6. Yao, C., Gao, X., \& Yu, Y. (2013). Wind speed forecasting by wavelet neural networks: A comparative study. Mathematical Problems in Engineering, 2013, 1-7.

7. Gnana Sheela, K., \& Deepa, S. N. (2013). A new algorithm to find number of hidden neurons in radial basic function networks for wind speed prediction in renewable energy systems. Journal of Control Engineering and Applied Informatics, 15(3), 30-37.

8. Ramesh Babu, N., \& Arulmozhivarman, P. (2013). Improving forecast accuracy of wind speed using wavelet transform and neural networks. Journal of Electrical Engineering and Technology, 8(3), 559-564.

9. Liu, X., Hu, Z. Q., \& Yang, G. (2013). Wind speed forecasting based on relevance vector machine and empirical mode decomposition. Advances in Information Sciences and Service Sciences (AISS), 5(10.32), 279-287.

10. Hu, Q., Su, P., Yu, D., \& Liu, J. (2014). Pattern based wind speed prediction based on generalized principal component analysis. IEEE Transactions on Sustainable Energy, 5(3), 866-874.

11. Ramesh Babu, N., \& Arulmozhivarman, P. (2014). Dynamic neural network based very short term wind speed forecasting. Wind Engineering, 30(2), 121-128.

12. Zhang, W., Su, Z., Zhang, H., Zhao, Y., \& Zhao, Z. (2014). Hybrid wind speed forecasting model study based on SSA and intelligent optimized algorithm. Abstract and Applied Analysis, 2014, 1-14.

13. Madhiarasan, M., \& Deepa, S. N. (2015). A novel criterion to select hidden neuron numbers in improved back propagation networks for wind speed forecasting. Applied Intelligence. https://doi.org/10.1007/s10489-015-0737-z.

14. Madhiarasan, M., \& Deepa, S. N. (2018). Determination of adequate hidden neurons in combo neural network using new formulation and fine tuning with IMGWOA for enrich wind-speed forecasting. International Journal of Applied Research on Information Technology and Computing, 9(1), 89-101.

15. Madhiarasan, M., \& Deepa, S. N. (2018). A novel method to select hidden neurons in ELMAN neural network for wind speed prediction application. WSEAS Transactions on Power Systems, 13, 13-30.

16. Madhiarasan, M., \& Deepa, S. N. (2017). Comparative analysis on hidden neurons estimation in multi layer perceptron neural networks for wind speed forecasting. Artificial Intelligence Review, 48(4), 449-471.

17. Madhiarasan, M., \& Deepa, S. N. (2017). A new hybridized optimization algorithm to optimize echo state network for application in solar irradiance and wind speed forecasting. World Applied Sciences Journal, 35(4), 596-614

18. Madhiarasan, M., \& Deepa, S. N. (2016). ELMAN neural network with modified grey wolf optimizer for enhanced wind speed forecasting. Circuits and Systems, 7(10), 2975-2995.

19. Madhiarasan, M., \& Deepa, S. N. (2016). New criteria for estimating the hidden layer neuron numbers for recursive radial basis function networks and its application in wind speed forecasting. Asian Journal of Information Technology, 15(21), 4377-4391.

20. Madhiarasan, M., \& Deepa, S. N. (2016). Performance investigation of six artificial neural networks for different time scale wind speed forecasting in three wind farms of coimbatore region. International Journal of Innovation and Scientific Research, 23(2), 380-411.

21. Madhiarasan, M., \& Deepa, S. N. (2016). Application of ensemble neural networks for different time scale wind speed prediction. Internationa Journal of Innovative Research in Computer and Communication Engineering, 4(5), 9610-9617

22. Madhiarasan, M., \& Deepa, S. N. (2016). Long-term wind speed forecasting using spiking neural network optimized by improved modified grey wolf optimization algorithm. International Journal of Advanced Research, 4(7), 356-368.

23. Zheng, D., Eseye, A. T., Zhang, J., \& Li, H. (2017). Short-term wind power forecasting using a double-stage hierarchical ANFIS approach for energy management in microgrids. Protection and Control of Modern Power Systems, 2(13), 1-10 
24. Chen, H., Zhang, J., Tao, Y., \& Tan, F. (2019). Asymmetric GARCH type models for asymmetric volatility characteristics analysis and wind power forecasting. Protection and Control of Modern Power Systems, 4(29), 1-11.

25. Madhiarasan, M., \& Deepa, S. N. (2016). Comprehensive study of various forecasting techniques for forecast of wind speed in the field of wind energy system. TIDEE (Teri Information Digest on Energy and Environment), 15(4), 439-457.

Submit your manuscript to a SpringerOpen ${ }^{\mathcal{O}}$ journal and benefit from:

- Convenient online submission

- Rigorous peer review

- Open access: articles freely available online

High visibility within the field

- Retaining the copyright to your article

Submit your next manuscript at $\boldsymbol{\sim}$ springeropen.com 